\title{
Ação educativa sobre a prevenção do papiloma vírus humano e do câncer de colo uterino: um relato de experiência
}

\author{
Educational action on the prevention of human papillomavirus and cervical cancer: an \\ experience report
}
Acción educativa sobre la prevención del virus del papiloma humano y el cáncer de cuello uterino: un informe de experiencia

\begin{abstract}
Danielle Oliveira da Silva ${ }^{1 *}$, David Alfredo Cordeiro da Silva ${ }^{1}$, Isabela Ceres da Silva Matos ${ }^{1}$, Laina Fernanda Sampaio Martins Paiva ${ }^{1}$, Maria Francilene da Silva Garcia¹, Dérmini de Sousa Ferreira ${ }^{1}$, Bruna Tayana Cardoso Mendonça ${ }^{1}$, Miriam Sousa Oliveira ${ }^{1}$, Aleiko Rafael Favacho Chagas ${ }^{1}$, Rubenilson Caldas Valois ${ }^{1}$.
\end{abstract}

\section{RESUMO}

Objetivo: Relatar a experiência acadêmica das intervenções de enfermagem frente a uma ação educativa em uma população adscrita, para prevenção ao câncer do colo do útero decorrente de infecção pelo Papiloma virus humano. Relato de experiência: Foi realizado por acadêmicos de Enfermagem de um centro universitário no formato de ação educativa associado a tecnologias leves. Realizada em uma sala de espera de Estratégia Saúde da Família e obtendo como público-alvo mulheres em rotinas de consulta ginecológica. Foi realizado a ação educativa dividida em duas etapas: a orientação com a utilização de banner e útero em acrílico, e na segunda etapa a roda de conversa e a dinâmica com perguntas e respostas. Considerações finais: Na assistência à saúde da mulher profissional de enfermagem exerce seu protagonismo incentivando a continuidade do processo de prevenção e garantindo a promoção de saúde como ferramenta principal, através do desenvolvimento de ações educativas voltadas ao controle das doenças mais prevalentes e manutenção do autocuidado e de consultas multidimensionais, favorecendo a identificação e prevenção dos determinantes do processo saúde-doença da população.

Palavras-chave: Câncer de colo uterino, Papilomavírus humano, Educação em saúde.

\begin{abstract}
Objective: To report the academic experience of nursing interventions facing an educational action in an enrolled population, for the prevention of cervical cancer resulting from infection by the human papilloma virus. Experience report: It was carried out by nursing students from a university center in the format of educational action associated with light technologies. Carried out in a Family Health Strategy waiting room and targ eting women in gynecological consultation routines. The educational action was divided into two stages: guidance with the use of a banner and acrylic uterus, and in the second stage the conversation wheel and dynamics with questions and answers. Final considerations: In the health care of female nursing professionals, she plays a leading role in encouraging the continuity of the prevention process and ensuring health promotion as the main tool, through the development of educational actions aimed at control ling the most prevalent diseases and maintaining self-care and of multidimensional consultations, favoring the identification and prevention of the determinants of the population's health-disease process.
\end{abstract}

Key words: Cervical cancer, Human papillomavirus, Health education.

${ }^{1}$ Centro Universitário Metropolitano da Amazônia (UNIFAMAZ), Belém - PA. *E-mail: dsosilva10@gmail.com 


\begin{abstract}
RESUMEN
Objetivo: Informar la experiencia académica de las intervenciones de enfermería frente a una acción educativa en una población inscrita, para la prevención del cáncer cervicouterino derivado de la infección por el virus del papiloma humano. Informe de experiencia: Fue realizado por estudiantes de enfermería de un centro universitario en el formato de acción educativa asociada a las tecnologías ligeras. Realizado en sala de espera de la Estrategia Salud de la Familia y dirigido a mujeres en rutinas de consulta gineco lógica. La acción educativa se dividió en dos etapas: orientación con el uso de estandarte y útero acrílico, y en la segunda etapa la rueda de conversación y dinámica con preguntas y respuestas. Consideraciones finales: En la atención de la salud de las profesionales de enfermería juega un papel protagónico en fomentar la continuidad del proceso de prevención y asegurar la promoción de la salud como herramienta principal, a través del desarrollo de acciones educativas orientadas al control de las enfermedad es más prevalentes y al mantenimiento de la propia -asistencia y de consultas multidimensionales, favoreciendo la identificación y prevención de los determinantes del proceso salud-enfermedad de la población.
\end{abstract}

Palabras clave: Cáncer de cuello uterino, Virus del papiloma humano, Educación para la salud.

\title{
INTRODUÇÃO
}

Segundo Filho ALS e Laranjeira CLS (2017) Câncer de Colo Uterino (CCU) é a quarta neoplasia que mais mata as mulheres no mundo, de maior prevalência nos países menos desenvolvidos e considerado um problema de saúde pública global, no Brasil são estimados 15 novos casos em cada 100 mil mulheres, onde as mais acometidas estão na faixa dos 40 anos de idade. Por outro lado, o CCU possui medidas eficazes de prevenção, tratamento e cura nos casos de baixa e média gravidade.

O Papiloma Vírus Humano (HPV) é uma Infecção Sexualmente Transmissível (IST) que causa lesões no tecido epitelial principalmente nas regiões anogenital e laringe, as pessoas sexualmente ativas se infectarão pelo menos uma vez na vida, mas apenas uma pequena parcela desenvolverá as verrugas e na maioria dos casos essas lesões somem de forma espontânea por ação do próprio sistema imune, apenas uma pequena parcela desenvolverá lesões oncológicas em um intervalo tempo de 10 a 20 anos podendo variar com a influência dos fatores de risco (CARVALHO NS, et al., 2021)

Ademais, o HPV infecta as células epiteliais do colo uterino sem causar processo inflamatório e ativação do sistema imune, instalando-se no interior das células interagindo com os genes que regulam as atividades do desenvolvimento e controle celular provocando a inativação de apoptose natural, enquanto ocorre a proliferação viral com lesões transitó rias e lesões percursoras de neoplasia (FILHO ALS e LARANJEIRA CLS, 2017).

Georg Papanicolaou, identificou a presença de células incomuns que acomete o epitélio uterino, as quantificando em cinco classes de malignidade. posteriormente as atipias celulares do colo uterino foram classificadas em nomenclaturas que discriminam grau de comprometimento das células da cérvice uterina para compreender o grau da lesão de forma mais sucinta, denominada de lesões Neoplásicas Intraepitelial Cervical (NIC), estão a lesão intraepitelial de baixo grau NIC I e as lesões intraepitelial de alto grau NIC II e NIC III que definem os estágios de leve, moderado e acentuado ou carcinoma in situ, atualmente o método mais usual é de Bethesda que aderiu conhecimentos para o melhor diagnóstico das células com afecções do HPV, classificando em lesões intraepitelial de baixo grau (LSIL) e alto grau (HSIL) (BRASIL, 2012).

Segundo Sousa ACO, et al. (2017), os comportamentos de risco para o CCU mais encontrados são a multiplicidade de parceiros sexuais, o tabagismo, uso prolongado de medicamentos contraceptivos orais, início precoce da atividade sexual, histórico de infecções vaginais, baixa suplementação de vitaminas, imunossupressão e falta de informações sobre a infecção do HPV.

As condições socioeconômicas das mulheres são fatores que implicam diretamente na identificação dos sinais e sintomas, em sua pesquisa ficou evidente que determinantes como idade, escolaridade e estado civil podem ser consideráveis para adoção de intervenções educativas para a prevenção do CCU, visto que muitas 
mulheres apenas conhece o HPV como uma IST e desconhecem sua relação com o câncer de colo uterino, na identificação dos sinais e sintomas ficou evidente que menos de $50 \%$ das mulheres conhecem os sintomas como verrugas vaginais, feridas genitais, corrimento, dor na relação sexual, dor no baixo ventre, coceira, dor ao urinar (ANDRADE AG, 2019).

A prevenção do câncer de colo de útero se dar pelo uso de preservativos nas relações sexuais, a realização do Papanicolau (PCCU) para rastreamento precoce e adesão a vacina contra as formas mais agressivas do HPV (ZACARIAS AS, et al., 2018). Para Gomes CHR, et al. (2011), o PCCU está entre as formas mais eficientes de diagnosticar o câncer no colo do útero, porém ainda há uma grande resistência das mulheres a procura dessa assistência por diversos fatores que inclui a falta de informação, medo de sentir dor, timidez, dificuldade na marcação do exame e a demora de resultados.

De acordo com Instituto Nacional de Câncer (INCA) (2016), o exame é indicado para mulheres a partir dos 25 anos, onde sua periodicidade deve ser a cada seis meses para resultados alterados e a cada 3 anos mediante dois resultados negativos consecutivos.

Com relação a imunização, trata-se de uma vacina quadrivalente que protege contra os tipos $6,11,16 \mathrm{e}$ 18 do HPV, incorporada no Programa Nacional de Imunização (PNI) desde do ano de 2014 com acesso gratuito através do sistema Único de Saúde (SUS), de forma gradativa foi ampliado a cobertura vacinal para meninas de 09 a 14 anos e meninos 11 a 14 anos, pesquisas apontam que houve alcance da meta nacional de cobertura vacinal, mas a adesão foi menor na segunda dose e que alguns estados e microrregiões não obtiveram boa cobertura vacinal sobre influência das condições demográficas, instrução e renda (MOURA LL, et al., 2021).

Além do público-alvo, mulheres entre 14 e 26 anos que obtiveram anormalidade nos exames anteriores do PCCU, público portador de HIV/AIDS e imunodeprimido entre 9 e 26 anos podem ter acesso a vacina (CALUMBY RJN, et al., 2020).

De acordo com Zardo GP, et al. (2014) e Cardial MFT, et al. (2019), foram criados dois tipos de vacinas com intuito de combater o HPV e tratar as lesões, a profilática e a terapêutica. A profilática é de maior eficácia chamada de quadrivalente atuando na resposta imunológica sendo suas partículas semelhantes ao vírus, os anticorpos produzidos pela vacina agem na mucosa genital prevenindo a infecção precocemente, em casos de infecção preexistente ou doenças já instaladas a vacina não possui ação, sendo necessário completar as três doses para a maior imunização.

Segundo Carvalho NS, et al. (2021), o DNA do HPV pode permanecer nas células inativo por meses ou até anos a partir da infecção inicial. O intuito do tratamento é eliminar os condilomas visíveis, não descartando a possibilidade do aparecimento de novas verrugas. Todavia existem tratamentos medicamentosos e ablativos, ambos devem ser trabalhados de forma individualizada considerando a peculiaridade de cada lesão.

Segundo Carneiro CPF, et al. (2019), o enfermeiro é um profissional habilitado desde a academia para prestar assistência de forma clínica e holística em todas as etapas da assistência na prevenção e tratamento ao câncer do colo do útero, dentre suas atribuições estão as ações educativas cont inuadas para sensibilizar as mulheres na redução dos fatores riscos, além de ser responsável pela coleta do exame citopatológico oncótico para diagnóstico precoce do CCU, assim possibilitando o tratamento inicial do câncer, redução dos agravos e acompanhamento a mulher durante a terapia, sendo fonte de informações sucintas sobre a terapêutica e seus ef eitos adversos promovendo um estado de segurança.

Portanto, as ações educativas para prevenção do CCU realizado pelo profissional de enfermagem é instrumento fundamental para atender as necessidades da comunidade na prevenção ao câncer, as ações educativas possibilitam fornecer informações capazes de corrigir entendimentos inadequados, mudar percepções, ajustar comportamentos e proporcionar a autorreflexão para melhorar seu quadro de saúde (OLIVEIRA JLT e FERNANDES BM, 2017).

Assim o objetivo do estudo foi relatar a experiência acadêmica das intervenções de enfermagem frente a uma ação educativa na comunidade para prevenção ao câncer do colo do útero decorrente de infecção pelo HPV. 


\section{RELATO DE EXPERIÊNCIA}

Trata-se de uma pesquisa qualitativa descritiva do tipo relato de experiência, realizado por acadêmicos de enfermagem em formato de uma ação educativa em uma sala de espera de uma ESF em Belém do Pará, no dia 15 de outubro de 2021, no período matutino, obtemos como público-alvo mulheres em rotina de consultas ginecológicas

A partir desse tema central foi iniciado pesquisa bibliográficas sobre CCU e HPV e a importância da enfermagem na promoção de saúde da mulher com intuito de favorecer prevenção CCU e HPV, visando relatar a experiência acadêmica das intervenções de enfermagem frente a uma ação educativa na comunidade para prevenção ao câncer do colo do útero decorrente de infecção pelo HPV. Dessa pesquisa elegeu-se o tema deste trabalho "Ação educativa sobre a prevenção do Papiloma vírus Humano e do Câncer de Colo Uterino", a qual utilizou-se uma tecnologia leve em forma de banner, associado a roda de conversa e dinâmica de balões. O trabalho foi desenvolvido no componente curricular Atenção de enfermagem à Saúde da Mulher.

O Curso de Bacharelado em Enfermagem de um Centro Universitário, possui em sua matriz curricular o Trabalho de Conclusão de Disciplina(TCD), que em cada semestre promove a iniciação científica e atividades de extensão aos estudantes de todos os semestres. Aos estudantes do quinto e sexto período de 2021 -2, o tema gerador foi a "Os cuidados da saúde nos ciclos da vida".

Onde iniciou-se reuniões para discutir qual seria a temática a bem como o público-alvo, de acordo com as pesquisas e reuniões com o orientador, a equipe optou pelo tema: Ação educativa sobre a prevenção do HPV e do Câncer de Colo Uterino. A organização deu-se em duas etapas: a primeira transcorreu com a fundamentação teórica para a construção de um banner, que em seu conteúdo apresentou entendimento amplo quanto o conceito de HPV e Câncer de Colo Uterino, sintomas, prevenção, fatores de risco com palavras e gravuras de simples compreensão, para facilitar o entendimento do público. Ademais, o banner demostrou-se uma ferramenta, de elucidação das argumentações apresentadas sobre as patologias, destacando a importância da prevenção.

A segunda etapa discutiu-se sobre o câncer do colo do útero, os tipos de HPV e suas lesões, focando na prevenção como o uso de preservativos e o exame do PCCU com demonstrações dos materiais utilizados no procedimento sendo, o espéculo, citobrush, espátula de Ayre, lâmina e o útero ilustrativo para facilitar o entendimento de como é realizado, a importância da vacina, o público-alvo sua eficácia. Durante a apresentação surgiram preocupações em relação a vacina, pois, muitas pensavam que havia estimulação aos adolescentes a vida sexual precoce.

Ao final, as pacientes puderam tirar suas dúvidas e compartilharam conhecimentos e vivências em relação a vacina contra o HPV, com os adolescentes em sua residência e sobre o PCCU. Observou-se que a maioria não fazia o exame há mais de dois anos por sentirem vergonha, medo e nervosismo, pois expõe sua genitália, ou seja, sua intimidade e pelas experiências que já tiveram.

A dinâmica foi realizada na sala de espera da ESF e contou com a participação de seis mulheres para a sua realização, organizada através de 6 balões com perguntas diversas sobre o tema escolhido, onde os balões deveriam ser estourados e suas correspondentes perguntas respondida pelo público ou pela equipe, caso o participante solicitasse a ajuda. Ao longo da apresentação o público se mostrou receptivo e participativo à proposta da dinâmica, onde os voluntários desenvolveram suas respostas de maneira singular e assertiva.

Além da atividade, a equipe solicitou que o grupo descrevesse em poucas palavras o que eles compreendiam sobre o câncer, onde foram obtidos os seguintes resultados: "medo", "dor", "morte", "preconceito" e "preocupação".

Através da dinâmica a equipe pode estabelecer um ambiente favorável ao processo de ensino aprendizagem, por meio do vínculo de confiança e proximidade, permitindo observar o feedback a respeito do que foi exposto. 


\section{DISCUSSÃO}

O conhecimento errôneo e insuficiente da comunidade sobre o HPV em relação a transmissão e prevenção é um fator de relevância para determinar pontos que possibilitam desenvolver estratégias capazes de mudar os comportamentos de riscos à saúde, dentre os achados, destaca que a maioria das pessoas estudadas não sabem o que é HPV nem a existência de vacina contra a infecção e não utilizam preservativo nas relações sexuais (ABREU MNS, et al., 2018). Ademais, Costa DAV e Ribeiro TR (2019) e Okamoto CT, et al. (2016), destacam que a alta taxa de infecção de HPV está atrelada à atividade sexual precoce de adolescentes e jovens que comumente falham na adesão de preservativos, está condição possui múltiplos fatores, sejam pelos conflitos das modificações biológicas nesta fase da vida ou por condições culturais da prática sexual, além da falta de entendimento e maturidade sobre as IST's.

Outrossim, a infecção pelo HPV possui alta prevalência epidemiológica quando analisado o perfil das mulheres com diagnóstico positivo da infecção, compilar os achados epidemiológicos das mulheres inf ectadas pelo HPV pode subsidiar informações capazes de identificar o perfil de mulheres com maior chance de progressão para lesões oncológicas, possibilitando aplicar intervenções que reduzam o alto quadro de prevalência de mulheres com CCU (AYRES ARG, et al., 2017).

A ação do enfermeiro educador é essencial para o rastreamento e diagnóstico precoce do CCU e HPV, dessa maneira incentivar as mulheres no que concerne a importância das consultas e exames periódicos para promoção da saúde e redução de novos casos, atentando-se a cultura, as condições socioeconômicas, a comunicação adequada para que haja compreensão, formas de prevenção, tratam ento e as etapas do PCCU. É fundamental que o profissional inclua os homens, muitos parceiros não compreendem que podem ser os transmissores do HPV e ignoram o uso de preservativos, um dos métodos de prevenção (NASCIMENTO NSS, et al., 2021).

Para Dantas CN, et al. (2012) e Carneiro CPF, et al. (2019) a atuação do enfermeiro na atenção primária é fundamental para prevenção e rastreamento do CCU, através da realização do PCCU, orientação e assistência contínua em saúde. Além disso, o profissional deve ter um olhar clínico qualificado para reconhecer sinais e sintomas sugestivos da doença durante a anamnese e exame físico, assim saber encaminhar a paciente para o tratamento. Vale ressaltar que a consulta de enfermagem permite estabelecer o vínculo de confiança com a paciente através do diálogo aberto, receptivo e disponível, proporcionando um ambiente favorável a expressar suas inseguranças e dúvidas em relação ao exame e à orientação sobre o autocuidado e prevenção de agravos.

Apesar do aumento gradual da idade e da inclusão do público masculino na cobertura vacinal, de ser uma vacina pertencente ao Programa Nacional de Imunização (PNI) oferecida gratuitamente na rede pública, apenas $32 \%$ dos municípios brasileiros conseguiram a devid a imunização com a segunda dose (MOURA LL, 2021).

A falta de informação e acesso ao serviço e até mesmo as crenças/medo de estar induzindo meninos e meninas ao início precoce da vida sexual diminuem a adesão a vacina. Em seus estudos Abreu MNS, et al, (2018), pontuam o baixo nível de escolaridade, a renda familiar insuficiente e pertencentes a lugares menos urbanizados como o grupo com menor conhecimento a respeito do HPV.

Contudo Carvalho NS (2020) e Melo MCSC (2012) dizem que é necessário investir em ações educativas com finalidade de prevenção e esclarecimento do exame Papanicolau, incentivo de uso de preservativos o início da vida sexual e a importância da vacina no período da adolescência. Dessa maneira, faz-se necessário a capacitação dos profissionais de saúde promovendo uma melhor qualidade na assistência com o intuito de criar empatia entre o profissional e o paciente, assim diminuindo a resistência negativa do usuário a procurar assistência.

Ao longo da ação, percebeu-se a predominância dos sentimentos de medo e preocupação, nesse contexto o enfermeiro é capacitado para minimizar esses sentimentos negativos, por se tratar de um profissional habilitado para estabelecer uma relação de proximidade, confiança e seguranç a com o paciente, desenvolver com a equipe multiprofissional ações de educação em saúde, rastreamento precoce, busca ativa para continuidade da assistência. Assim, faz-se necessário que os profissionais mantenham a educação continuada com intuito de qualificar a assistência prestada. 


\section{REFERÊNCIAS}

1. AYRES ARG, et al. Infecção por HPV em mulheres atendidas pela Estratégia Saúde da Família. Revista de Saúde Pública, 2017;51(92): 1-11.

2. ABREU MNS, et al. Conhecimento e percepção sobre o HPV na população com mais de 18 anos de Ipatinga, MG, Brasil. Ciência \& Saúde Coletiva, 2018;23: 849-860.

3. ANDRADE AG, et al. HPV x câncer de colo de útero: O conhecimento das mulheres na região central de um município referência da região de saúde ilha do Bananal-TO. Revista Amazônia Sciencie \& Healt, 2019;7(2): 70-78.

4. BRASIL. Instituto Nacional de Câncer. Diretrizes brasileiras para o rastreamento do câncer do colo do útero. 2016 . Disponível https://www.inca.gov.br/sites/ufu.sti.inca.local/files/media/document/diretrizesparaorastreamentodocancerdocolodou tero_2016_corrigido.pdf.

5. BRASIL. Nomenclatura Brasileira para Laudos Citopatológicos Cervicais. 2012. Disponível em: https://pesquisa.bvsalud.org/bvsms/resource/pt/mis-40111. Acessado em: 13 de dezembro de 2021.

6. COSTA DAV, RIBEIRO TR. Vulnerabilidade de jovens e adolescentes a infecção por HPV e as condutas preventivas da enfermagem. Temas em Educação e Saúde, 2019;15:217-233.

7. CALUMBY RJN, et al. Papiloma vírus humano (HPV) e neoplasia cervical:im portância da vacinação. Brazilian joumal of health Review.2020;3: 1610-1628.

8. CARDIAL MFT, et al. Papilomavirus humano (HPV). Feminina. 2019;47(2):94-100.

9. CARNEIRO CPF, et al. O Papel do enfermeiro frente ao câncer de colo do uterino. Revista Eletrônica Acervo Saúde, 2019;35: 1-9.

10. CARVALHO NS, et al. Protocolo Brasileiro para infecções sexualmente transmissíveis 2020: infecção pelo papilomavírus humano (HPV). Revista Epidemiologia e Serviços de Saúde, 2021;30(4):1-12.

11. DANTAS CN, et al. A consulta de enfermagem na prevenção do câncer cérvico-uterino para mulheres que a vivenciaram. Revista da Rede de Enfermagem do Nordeste, 2012;13(3):591-600.

12. FILHO ALS, LARANJEIRA CLS. Manual sogimig de genecologia e obstetrícia. 6aㅡ ed. Rio de janeiro: Cientifica LTDA, 2017,298p.

13. GOMES CHR, et al. Câncer Cervicouterino: Correlação entre Diagnóstico e Realização Prévia de Exame Preventivo em Serviço de Referência no Norte de Minas Gerais. Revista Brasileira de Cancerologia. 2012; 1(58):41-45.

14. NASCIMENTO NSS. A importância do enfermeiro na prevenção do câncer de colo do útero. Revista Científica Multidisciplinar Núcleo do Conhecimento. 2021;6(15):73-88.

15. MELO MCSC, et al. O Enfermeiro na Prevenção do Câncer do Colo do Útero: o Cotidiano da Atenção Primária. Revista Brasileira de Cancerologia. 2012;3(58):389-398.

16. MOURA LL, et al. Cobertura da vacina papilomavírus humano (HPV) no Brasil: heterogeneidade espacial e entre coortes etárias. Revista brasileira de epidemiologia, 2021;21(24):1-12.

17. OKAMOTO CT, et al. Perfil do Conhecimento de Estudantes de uma Universidade Particular de Curitiba em relação ao HPV e Sua Prevenção. Revista Brasileira de Educação Médica. 2016;40(4): 611-620.

18. OLIVEIRA JLT, FERNANDES BM. Intervenções de enfermagem na prevenção do cérvico-uterino:perspectivas das clientes. Revista enfermagem UERJ, 2017;25, 1-6.

19. SOUSA ACO, et al. Caracterização das alterações citopatológicas e fatores de riscos associados ao desenvolvimento do câncer de colo de útero, Revista Uningá Review, 2017;30: 67-71.

20. ZACARIAS AS, et al. Mulheres portadoras do câncer de colo e útero em tratamento por braquiterapia. Revista Thêma et Scientia; 2018;8(1): 119-133.

21. ZARDO GP, et al. Vacina como agente de imunização contra o HPV. Ciência e Saúde Coletiva, 2013;3799-3808. 